\title{
TRANSMISIÓN EXPERIMENTAL DEL VIRUS DEL MAL DE RÍO CUARTO POR Delphacodes kuscheli
}

\author{
GRACIELA A. TRUOL ${ }^{1}$, TOMIO USUGI ${ }^{2}$, JUTARO HIRAO ${ }^{2}$, JOEL D. ARNEODO ${ }^{3}$, \\ M. PAZ GIMÉNEZ PECCI ${ }^{1} \&$ IRMA G. LAGUNA ${ }^{1}$
}

\begin{abstract}
${ }^{1}$ IFFIVE - INTA; ${ }^{2}$ Convenio INTA - JICA; ${ }^{3}$ CONICET. Instituto de Fitopatología y Fisiología Vegetal (IFFIVE) - Instituto Nacional de Tecnología Agropecuaria (INTA). Cno. a 60 cuadras km. 5 1/2, (5119) Córdoba, Argentina. Tel. +54 351 4973636/4974343, fax +54 351 4974330, e.mail: gtruol@inta.gov.ar
\end{abstract}

(Aceptado para publicar en 05/12/2000)

Autor para correspondencia: Graciela A. Truol

TRUOL, G. A., USUGI, T., HIRAO, J., ARNEODO, J. D., GIMÉNEZ PECCI, M. P. \& LAGUNA, I. G. Transmisión experimental del virus del mal de Río Cuarto por Delphacodes kuscheli. Fitopatologia Brasileira 26:39-44. 2001.

\section{RESUMEN}

Entre las enfermedades que afectan al cultivo de maíz (Zea mays) en Argentina, la producida por el virus del mal de Río Cuarto (MRCV) es la más importante. El MRCV pertenece a la familia Reoviridae, género Fijivirus, y su propagación en la naturaleza es realizada por Delphacodes kuscheli (Hemiptera: Delphacidae). La modalidad de transmisión para los miembros de este género de virus es persistente propagativa. Se estableció la necesidad de ajustar un sistema de transmisión eficiente del virus para estudios de caracterización, partiendo de poblaciones libres de virus criadas en laboratorio, para lo cual se ensayaron distintos períodos de adquisición, latencia e inoculación, evaluándose además un rango de hospedantes diferenciales. Se lograron obtener insectos libres de virus en cantidad suficiente para llevar a cabo los trabajos, mediante su cría en fitotrones y cámaras aclimatadas.
La transmisión experimental del MRCV se efectuó exitosamente, bajo idénticas condiciones, empleando períodos de adquisición, latencia e inoculación de dos, 10 y uno día respectivamente para los cereales de grano fino y de dos, $10 \mathrm{y}$ dos días para el maíz. Se infectaron de este modo las siguientes especies: maíz, cebada (Hordeum vulgare), avena (Avena sativa), trigo (Triticum aestivum), centeno (Secale cereale), grama rhodes (Chloris gayana) y alpiste (Phalaris canariensis). La detección del virus en las plantas inoculadas se efectuó mediante pruebas serológicas, análisis de dsRNA en electroforesis en gel de poliacrilamida (obteniéndose las 10 bandas típicas de los fijivirus) y microscopía electrónica, detectándose las partículas isométricas de entre 60 y $70 \mathrm{~nm}$ de diámetro.

Palabras clave: transmisión por vectores, Delphacidae, Fijivirus, cereales.

\section{ABSTRACT \\ Experimental transmission of Mal del Rio Cuarto virus by Delphacodes kuscheti}

The disease caused by the "Mal de Rio Cuarto virus" (MRCV) is one of the most important diseases among those affecting maize (Zea mays) crops in Argentina. The MRCV belongs to the Reoviridae family, within the Fijivirus genus. It is spread in nature by Delphacodes kuscheli (Hemiptera: Delphacidae). The manner of transmission of the members of this virus genus is persistent propagative. An efficient virus transmission system was arranged in order to perform the various characterisation studies. These studies were carried out with healthy vector populations raised in the laboratory. Different acquisition, latency and inoculation periods were tested and a range of differential hosts was also evaluated, by breeding in phytotrons and controlled atmosphere chambers. A sufficient number of virus-free insects could thus be obtained to perform work. Experimental transmission of MRCV was successfully accomplished under identical conditions with acquisition, latency and inoculation periods of two, 10 and one days for fine grain cereals and two, 10 and two days for maize respectively. The following species were infected in this manner: maize (Zea mays), barley (Hordeum vulgare), oats (Avena sativa), wheat (Triticum aestivum), rye (Secale cereale), grama rhodes (Chloris gayana) and birdseed (Phalaris canariensis). Virus detection in inoculated plants was performed by means of serological tests, electrophoresis of the dsRNA in polyacrylamide gel (which showed the 10 typical bands of the fijiviruses) and electron microscopy, which showed $60-70 \mathrm{~nm}$ isometric particles.

\section{INTRODUCCIÓN}

El mal de Río Cuarto es la enfermedad más importante del cultivo de maíz (Zea mays L.) en Argentina (Lenardon et al., 1998; Rodríguez Pardina et al, 1998). El área endémica de la virosis se encuentra en la zona próxima a la localidad de Río Cuarto (Provincia de Córdoba, Argentina), donde fue detectada por primera vez al final de la década del 60 (Nome et 
al., 1981; Lenardon et al., 1999). Su distribución se fue ampliando progresivamente, alcanzando en la actualidad gran parte del área maicera argentina (Laguna \& Di Feo, 1997). En el año 1997 se registró una severa epidemia que causó pérdidas de alrededor de U\$S 120.000.000 (Lenardon et al., 1999).

El virus del mal de Río Cuarto (MRCV) pertenece la familia Reoviridae, género Fijivirus, sus partículas son de forma icosaédrica, de aproximadamente $70 \mathrm{~nm}$ de diámetro y contienen 10 segmentos de doble cadena de RNA. Se transmite en la naturaleza por Delphacodes kuscheli Fennah (Hemiptera: Delphacidae) (Remes Lenicov et al., 1985). La modalidad de transmisión de los fijivirus, como el Maize rough dwarf virus (MRDV) y demás miembros del género, es persistente propagativa (el virus se multiplica dentro del cuerpo del vector, el cual permanece infectivo durante toda su vida) (Milne \& Lovisolo, 1977). El MRCV infecta numerosas especies de la familia Poaceae. Entre ellas se encuentran varios cultivos de importancia además del maíz, tales como trigo (Triticum aestivum L.), avena (Avena sativa L.), cebada (Hordeum vulgare L.), sorgo (Sorghum halepense L.), centeno (Secale cereale L.), y triticale (Triticum x Secale) (Marinelli et al., 1988; Conci et al., 1992; Laguna \& Di Feo, 1997; Rodríguez Pardina et al, 1998).

Hasta el momento, los estudios de transmisión realizados fueron efectuados con insectos infectados provenientes de campo (Ornaghi et al., 1993), por lo que se planteó como objetivo del presente trabajo el ajuste de la transmisión experimental del virus, utilizando poblaciones de insectos sanos criados en laboratorio, a fin de establecer los períodos de adquisición, latencia e inoculación necesarios para asegurar una transmisión eficiente y determinar el posible rango de hospedantes del MRCV.

\section{MATERIALES Y MÉTODOS}

\section{Obtención y mantenimiento de poblaciones sanas del insecto vector}

Se realizaron redadas de recolección del vector $D$. kuscheli en pasturas durante el mes de noviembre, momento de mayor nivel poblacional del insecto en la zona endémica (March et al., 1993). Éstos fueron alojados en macetas con tubos plásticos provistos de aperturas de aireación cubiertas por tejido del tipo 'voile', conteniendo plantas jóvenes de cebada y trigo, especies por las que $D$. kuscheli muestra una marcada preferencia. Las poblaciones así acondicionadas se mantuvieron en salas de cría y en fitotrones, a una temperatura constante de $24^{\circ} \mathrm{C}$, fotoperíodo de $12 \mathrm{~h}$ de luz y $50 \%$ de humedad. Se permitió a los insectos adultos, subdivididos en lotes, oviponer por un lapso de 2 días, luego de los cuales fueron transferidos a nuevas plantas. Cada uno de estos lotes fue además sometido a experimentos de transmisión en trigo y/o avena, descartándose posteriormente las generaciones de insectos provenientes de lotes infectados, a fin de lograr poblaciones libres de virus, ante la eventual existencia de transmisión transovárica, hecho que está siendo estudiado. Se midió el período de tiempo necesario para la emergencia de las ninfas, así como la duración de cada uno de los cinco estadíos ninfales bajo las condiciones anteriormente descriptas.

\section{Inóculo inicial}

El virus fue aislado de plantas de avena provenientes de la zona endémica de la enfermedad, con severos síntomas de enaciones, hojas con borde cortado, 'tirabuzón' y enanismo. La presencia del MRCV en las plantas fue confirmada mediante pruebas serológicas (DAS - ELISA), empleando el antisuero correspondiente (Giménez Pecci et al., 1986; Rodríguez Pardina et al., 1998). Se seleccionaron para los ensayos de transmisión aquellas plantas que registraron mayores lecturas de absorbencia.

\section{Ensayos de transmisión}

En todos los casos se utilizaron insectos sanos provenientes de la cría en laboratorio. Se trabajó con ninfas de tercer y cuarto estadío, y con adultos jóvenes. Éstos fueron colocados, aproximadamente en número de 100, sobre las plantas fuente de inóculo (trigo y avena), para el período de adquisición. El período de latencia transcurrió sobre plantas de trigo sanas, y para el periodo de acceso a inoculación se utilizaron lotes de aproximadamente 15 individuos en grupos de 4 - 5 plantas de avena, trigo, cebada o maíz al estado de coleoptile o primera hoja. Para el confinamiento de los insectos se recurrió a los tubos plásticos descriptos anteriormente. Se intentó la transmisión con los tiempos de adquisición, latencia e inoculación indicados en la Tabla 1, usados para otras virosis de modalidad persistente (Milne \& Lovisolo, 1977), empleando en cada ensayo 50 plantas por especie vegetal probada.

Los ensayos se llevaron a cabo dentro de fitotrones, bajo las condiciones antes mencionadas para la cría.

Las plantas inoculadas se conservaron en invernadero hasta la aparición de síntomas, determinándose así la susceptibilidad de la especie vegetal y el tiempo de incubación del virus en la misma.

\section{Rango de hospedantes}

Se probaron las siguientes especies y cultivares: $Z$. mays cvs. Laser y Pioneer 3467, H. vulgare cvs. Baroy, Ranquelina, Quilmes Ayelén y Quilmes Alfa, A. sativa cv.

TABLA 1 - Tiempos de adquisición, latencia e inoculación utilizados en los ensayos de transmisión experimental del MRCV por Delphacodes kuscheli

\begin{tabular}{cccc}
\hline \hline Ensayo & $\begin{array}{c}\text { Tiempo de período } \\
\text { de adquisición } \\
\text { (días) }\end{array}$ & $\begin{array}{c}\text { Período de } \\
\text { latencia } \\
\text { (días) }\end{array}$ & $\begin{array}{c}\text { Período de } \\
\text { inoculación } \\
\text { (días) }\end{array}$ \\
\hline A & 1 & 2 & 1 \\
B & 1 & 10 & 1 \\
C & 2 & 10 & 1 \\
D & 2 & 10 & 2 \\
\hline
\end{tabular}


Tucana, T. aestivum cv. ProINTA Federal, S. cereale, Chloris gayana Kunth. y Phalaris canariensis L. Estas especies ya fueron utilizadas como indicadoras por otros autores en la caracterización de miembros del género Fijivirus, tales como el Maize rough dwarf virus (MRDV), Oat sterile dwarf virus (OSDV) y Rice black streaked dwarf virus (RBSDV) (Milne \& Lovisolo, 1977; Brunt et al., 1996).

\section{Detección del virus en las plantas inoculadas}

Las plantas sintomáticas fueron sometidas a diversas pruebas para confirmar la presencia del virus.

Pruebas serológicas (DAS - ELISA): se realizaron a partir de muestras de hoja y raíz, maceradas en solución tampón de extracción (PBS $+0,05 \%$ Tween $20+2 \%$ polyvinyl pyrrolidone) en relación $1 / 5(\mathrm{P} / \mathrm{V})$. La gamaglobulina específica para MRCV y el conjugado fueron empleados en relación 1:1000 (Giménez Pecci et al., 1986). Se utilizaron placas Nunc Immunoplate MaxiSorp de 96 pocillos, y el método general seguido fue el de Clark \& Adams (1977).

Doble cadena de RNA: se aplicó electroforesis (PAGE) en análisis de raíces y hojas, para detección de dsRNA en gel de poliacrilamida $10 \%$ y tinción con plata, de acuerdo al protocolo de Giordano et al. (1991), modificado por Giménez Pecci et al. (1991).

Microscopía electrónica: pequeñas porciones de hoja con síntomas de borde cortado, color verde oscuro y enaciones (en el caso del maíz) fueron incluidas en resina Spurr para su corte en ultramicrótomo (RMC MT6000-XL) y observación al microscopio electrónico de transmisión (JEOL JEM 1200 EX II) en magnificaciones de 8000 a $10000 \mathrm{x}$. Las secciones ultrafinas, de $100 \mathrm{~nm}$ de espesor, fueron contrastadas en acetato de uranilo $2 \%$ y citrato de plomo. Se registró la presencia del virus y posibles alteraciones.

\section{RESULTADOS Y DISCUSIÓN}

\section{Obtención y mantenimiento de poblaciones sanas del insecto vector}

Se obtuvo un excelente rendimiento de la cría, determinándose que el tiempo promedio para el desarrollo de una generación abarca aproximadamente 30 días bajo las condiciones estudiadas. Partiendo de grupos de 10 hembras y 7 machos que permanecieron durante 2 días en las jaulas de oviposición, se lograron alrededor de 200 ninfas/jaula. El período de desarrollo de los huevos y la duración de los estadíos ninfales se resumen en la Tabla 2.

\section{Ensayos de transmisión}

Se logró la transmisión del MRCV en condiciones de laboratorio, empleando períodos de adquisición, latencia e inoculación de 2, 10 y 1 día, respectivamente, en el caso de los cereales de grano fino y de 2, 10 y 2 días cuando se trabajó con maíz, ya que en éste último se observó que el insecto no
TABLA 2 - Período medio de desarrollo de huevos y estadíos ninfales deDelphacodes kuschelibajo condiciones controladas de temperatura $\left(24^{\circ} \mathrm{C}\right)$, humedad relativa $(50 \%)$ y fotoperíodo $(12 \mathrm{~h}$ de luz)*

\begin{tabular}{lc}
\hline Estadío & $\begin{array}{c}\text { Duración promedio } \\
\text { (en días) } * *\end{array}$ \\
\hline Huevo & 8,5 \\
Primer estadío & 4,0 \\
Segundo estadío & 2,5 \\
Tercer estadío & 3,0 \\
Cuarto estadío & 4,0 \\
Quinto estadío & 5,5 \\
Período de preoviposición & 4,0 \\
\hline
\end{tabular}

* En fitotrón marca Conviron, modelo EF7.

**La duración promedio se calculó en base a 250 individuos por estadío.

se alimenta inmediatamente de la planta debido a su no preferencia por esta especie (ensayos C y D de la Tabla 1). En el país, estudios de transmisión del MRCV realizados con insectos de la especie $D$. kuscheli infectados naturalmente en el campo, demuestran que es suficiente un período de inoculación de 1 hora, aunque si esta etapa se extiende, la eficiencia se incrementa (Ornaghi et al., 1993).

La transmisión fue posible tanto con ninfas como con adultos, pero se comprobó la ventaja de la adquisición del virus por parte de las primeras debido a que los adultos deterioran las plantas fuente de inóculo, y porque el prolongado período de latencia del virus en el cuerpo del vector hace que su vida útil como transmisor del MRCV sea menor. A los efectos de multiplicar el inóculo, se evidenció la necesidad de utilizar cereales de invierno (trigo, avena y cebada), ya que en éstos la transmisión es más eficiente que en maíz (Tabla 3) y es menor el tiempo de aparición de síntomas. Se observó una gran mortandad de insectos durante el período de latencia (aproximadamente un 50\%), por lo que se debió partir de una cantidad elevada de individuos para lograr un buen número de ejemplares infectivos, finalizados los períodos de acceso a adquisición y de latencia. Comenzando el período de acceso a adquisición con 100 ninfas, se contó con insectos suficientes para infectar unas 15 - 20 plantas por día durante al menos una semana, en el caso de los cereales de invierno.

TABLA 3 - Tasa de transmisión del virus del mal de Río Cuarto en diferentes especies de gramíneas

\begin{tabular}{lcc}
\hline Especie hospedante & $\begin{array}{c}\text { Períodos de adquisición, } \\
\text { latencia e inoculación } \\
\text { empleados (días) }\end{array}$ & $\begin{array}{c}\mathbf{N}^{0} \text { de plantas } \\
\text { inoculadas/ } \\
\text { probadas }\end{array}$ \\
\hline Zea mays cv. Laser & $2-10-2$ & $7 / 50$ \\
Hordeum vulgare cv. Baroy & $2-10-1$ & $23 / 50$ \\
Avena sativa cv. Tucana & $2-10-1$ & $24 / 50$ \\
Triticum aestivum cv. ProINTA Federal & $2-10-1$ & $26 / 50$ \\
\hline
\end{tabular}




\section{Rango de hospedantes}

Fue posible transmitir la virosis a todas las especies de gramíneas probadas (Tabla 4). Este rango de hospedantes difiere levemente del de otros virus del géneroFijivirus (Milne \& Lovisolo, 1977). Los síntomas más importantes en todas las especies fueron: hojas con borde recortado o en tirabuzón, con color verde más oscuro (esto último en cereales de grano fino), enaciones, nervaduras hinchadas, enanismo y achaparramiento (Tabla 4). En cereales de invierno se observó, por primera vez, que la enfermedad se puede sistematizar en un macollo, permaneciendo los otros normales, y que el virus no es detectado serológicamente en estos últimos (Figura 1). El tiempo transcurrido entre la inoculación y la aparición de síntomas varió entre 2 y 8 semanas en los cereales de invierno y entre 8 y 12 semanas para el maíz (Tabla 4). Se destaca la rapidez con que se manifiesta la presencia del virus en trigo cv. ProINTA Federal, además de su alta susceptibilidad, por lo que se propone su uso como indicador. También se sugiere el empleo del maíz Pioneer 3467 para estas pruebas, ya que es susceptible y produce enaciones muy evidentes, síntoma inequívoco de infección por MRCV (Lenardon et al., 1999).

TABLA 4 - Rango de hospedantes, tiempo de incubación y síntomas inducidos por el virus del mal de Río Cuarto

\begin{tabular}{lcl}
\hline Especie hospedante & $\begin{array}{c}\text { Tiempo de } \\
\text { incubación } \\
\text { (semanas) }\end{array}$ & \multicolumn{1}{c}{ Síntomas* } \\
\hline $\begin{array}{l}\text { Zea mays cvs. Laser, Pioneer } \\
\quad 8-12\end{array}$ & bhc, enc, nh, enm, ach \\
$\begin{array}{l}\text { Hordeum vulgare cvs. Baroy, } \\
\text { Ranquelina, Quilmes Ayelén, }\end{array}$ & $3-5$ & enm, cvo, bhc, ht \\
$\quad$ & \\
$\quad \begin{array}{l}\text { Quilmes Alfa } \\
\text { Avena sativa cv. Tucana }\end{array}$ & $3-5$ & enm, cvo, bhc, ht \\
Triticum aestivum cv. ProINTA & $2-5$ & bhc, ht, cvo, enm \\
$\quad \begin{array}{l}\text { Federal } \\
\text { Secale cereale }\end{array}$ & $6-8$ & bhc, enm \\
Chloris gayana & $5-8$ & bhc \\
Phalaris canariensis & $3-5$ & enc, cvo
\end{tabular}

*bhc: borde de hoja cortado, enc: enaciones, nh: nervaduras hinchadas, enm: enanismo, ach: achaparramiento, cvo: color verde más oscuro en hojas, ht: hojas en tirabuzón

\section{Detección del virus en las plantas inoculadas}

Pruebas serológicas (DAS - ELISA): Las plantas con la sintomatología descripta registraron resultados positivos, tanto en hoja como en raíz, detectándose valores de absorbencia leve a moderadamente más altos en ésta última, como ya fue reportado por Giménez Pecci et al. (1997), entre otros autores, en cereales infectados naturalmente en el campo. De todos modos, en los cereales de grano fino los valores de concentración relativa del virus en hoja fueron altos, especialmente en trigo, dato que resulta de interés debido a que la adquisición del patógeno se efectúa desde este órgano vegetal.

Doble cadena de RNA: Este análisis reveló la presencia de los 10 segmentos de cadena doble de RNA, coincidentes con el perfil electroforético esperado (Figura 2).
Microscopía electrónica: En todos los casos se encontraron viroplasmas, con partículas completas e incompletas y viriones aislados (Figura 3), en las células del floema y acompañantes, similares a las descriptas para el MRCV por Nome et al. (1981) en material infectado naturalmente en el campo.

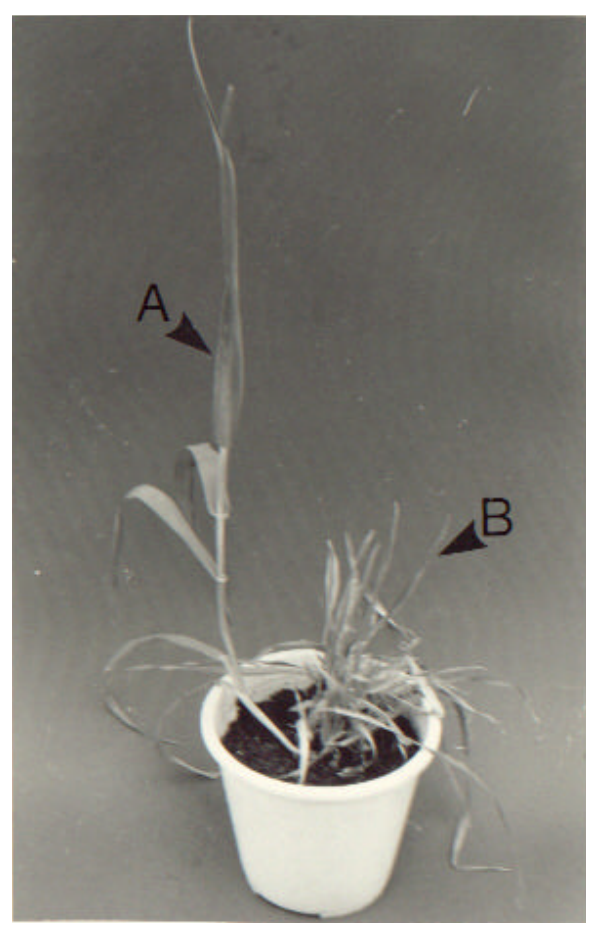

FIG. 1 - Planta de cebada infectada experimentalmente con el virus del mal de Río Cuarto mostrando macollo sano (A) y enfermo (B).

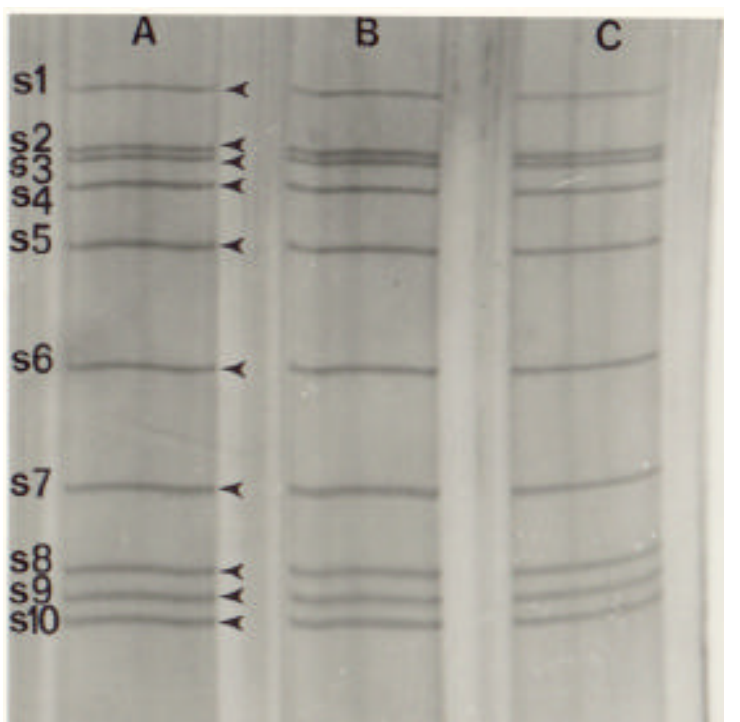

FIG. 2 - Electroforesis en gel de poliacrilamida, con las 10 bandas de dsRNA características de los fijivirus, en tres muestras de trigo provenientes de plantas infectadas experimentalmente con el virus del mal de Río Cuarto. 


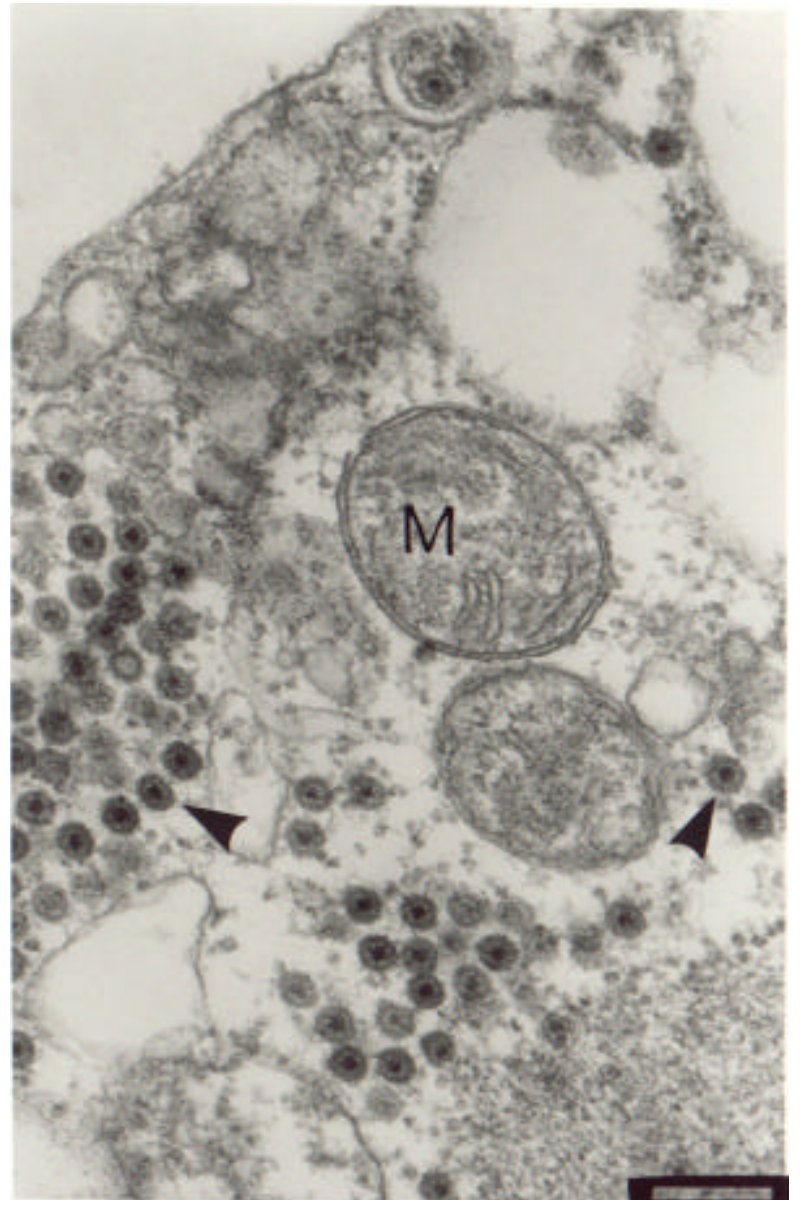

FIG. 3 - Partículas del virus del mal de Río Cuarto (flechas) cercanas a mitocondrias $(M)$ en citoplasma de célula acompañante del floema, en planta de cebada infectada experimentalmente

\section{AGRADECIMIENTOS}

Los autores agradecen al Instituto Nacional de Tecnología Agropecuaria (INTA), Japanese International Cooperation Agency (JICA), Consejo de Investigaciones de la Provincia de Córdoba (CONICOR) y Fondo Nacional de Ciencia y Técnica (FONCyT) por proveer los fondos necesarios para la realización y publicación de este trabajo.

\section{REFERENCIAS BIBLIOGRÁFICAS}

BRUNT, A., CRABTREE, K., DALLWITZ, M., GIBBS, A. \& WATSON, L. Viruses of plants. University Press, Cambridge. CAB International. 1996.

CLARK, M.E. \& ADAMS, A.N. Characteristics of microplates methods of Enzyme Linked Immunosorbent Assay for detection of plant viruses. Journal of General Virology 34:475-483. 1977.

CONCI, L., VALDIVIA, M. \& NOME, S. Prospección del virus del enanismo rugoso del maíz (MRDV, "Mal de Río IV") en malezas hospedantes mediante la técnica de ELISA y de IEM. Fitopatología 27:26-32. 1992.

GIMÉNEZ PECCI, M.P., MILNE, R. \& NOME, S.F. Purificación y obtención de antisuero de las partículas del virus causal del Mal de Río Cuarto. Actas, II Congreso Argentino de Virología. Córdoba, Argentina. 1986. Resumen $\mathrm{N}^{\circ} 23$.

GIMÉNEZ PECCI, M.P., CONCI, L.R., VALDIVIA, B., CONCI, V.C., HOPP, H.E., LAGUNA, I.G. \& NOME, S.F. Algunas alternativas de diagnóstico del virus del "mal de Río Cuarto" (Maize Rough Dwarf Virus MRDV). Actas, Taller de Actualización sobre Mal de Río Cuarto. Pergamino, Argentina. 1991. pp. 78-86.

GIMÉNEZ PECCI, M.P., LAGUNA, I.G., DAGOBERTO, E., TRUOL, G., RODRÍGUEZ PARDINA, P.E., CONCI, L.R., FERRER, F. \& ORNAGHI, J. Cebada (Hordeum vulgare L.), un nuevo hospedante natural del virus del mal de Río Cuarto (MRCV) en Argentina. Actas, VI Congreso Nacional de Maíz. Pergamino, Argentina. 1997. Tomo I, II-32.

GIORDANO, M.O, BASNEC, S.N., NATES, S.V., BENNUN, F. \& DEPETRIS, A.R. Rapid techniques for diagnostic and epidemiological studies of rotavirus infection. Journal of Virological Methods 35:59-63. 1991.

LAGUNA, I.G. \& DI FEO, L. DEL V. PROMARC (Proyecto Mal de Río Cuarto). Hoja Informativa $N^{o}$ 3. Instituto de Fitopatología y Fisiología Vegetal (IFFIVE-INTA), Córdoba, Argentina. 1997.

LENARDON, S.L., MARCH, G.J., NOME, S.F. \& ORNAGHI, J.A. Recent Outbreak of "Mal de Río Cuarto Virus" on Corn in Argentina. Plant Disease 82:448. 1998. (Note).

LENARDON, S.L., MARCH, G.J. \& ORNAGHI, J.A. Virus del mal de Río Cuarto en maíz. In: Enfermedades de los Cultivos Extensivos e Intensivos. Hoja informativa. Instituto de Fitopatología y Fisiología Vegetal (IFFIVEINTA), Córdoba, Argentina. 1999.

MARCH, G.J., ORNAGHI, J.A., BEVIACQUA, J.E., SÁNCHEZ, G. \& GIUGGIA, J. Aportes para el desarrollo de una estrategia de manejo del mal de Río Cuarto. Resúmenes del Workshop "Mal de Río Cuarto del Maíz”. Córdoba, Argentina. 1993.

MARINELLI, A., MUÑOZ, J., LENARDON, S. \& MARTINO, C. Detección de un reovirus semejante al causal del Mal de Río Cuarto del maíz en sorgo de alepo (Sorghum halepense L.) y mijo (Panicum miliaceum L.). Actas, III Congreso Nacional de Maíz. Pergamino, Argentina. 1988. Tomo III, pp. 1-10.

MILNE, R.G. \& LOVISOLO, O. Maize Rough Dwarf and related viruses. Advances in Virus Research 21:267-341. 1977.

NOME, S.F., LENARDON, S.L., RAJU, B.C., LAGUNA, I.G., LOWE, S.K. \& DOCAMPO D. Association of Reovirus-like particles with "Enfermedad de Río Cuarto" of maize in Argentina. Phytopathologische Zeitschrift 101:7-15. 1981 . 
ORNAGHI, J.A., MARINELLI, A.D., MARCH, G.J., BOITO, G.T. \& RODRÍGUEZ PARDINA, P. Transmisión del virus causal del mal de Río Cuarto por Delphacodes kuscheli Fennah a cultivos y malezas. Resúmenes Workshop "Mal de Río Cuarto del Maíz". Córdoba, Argentina. 1993.

REMES LENICOV, A.M. DE, A. TESON, E. DAGOBERTO $\&$ N. HUGUET. Hallazgo de uno de los vectores del mal de Río Cuarto en maíz. Gaceta Agropecuaria. V:251258.1985.

RODRÍGUEZ PARDINA, P.E., GIMÉNEZ PECCI, M.P., LAGUNA, I.G., DAGOBERTO, E. \& TRUOL, G. Wheat: A new natural host for the mal de Río Cuarto virus in the endemic disease area, Río Cuarto, Córdoba Province, Argentina. Plant Disease 82:149152. 1998. 